Trabajos de Prehistoria

48, 1991, pp. 357-363

\title{
RECIENTES APORTACIONES A LAS RELIGIONES PRIMITIVAS DE LA HISPANIA AN TIGUA
}

\author{
POR \\ J. M. BLAZQUE: \\ M. P. GARCIA-GELABERT (")
}

\begin{abstract}
RESUMEN En este trabajo tratamos y comentamos un cierto número de teónimos Vortiacio, Larrahi, Errensa, Lacubegi, Porconis, Peremusta, Selastse, Bandua, Cossus, Nabia, Reva, Neito, Vaelico. Ninimedius Seddiagus, Erudinus, Evedutonius Barciaecus, Dulovius - Tabalienus, Parameco. Basándonos en los téonimos y en sus estudios se hace una disquisición sobre la religión, la vida espiritual de las poblaciones celtas, del norte y celtíberas.
\end{abstract}

\begin{abstract}
We present and discuss a certain number of theonimes Vortiacio, Larrahi, Errensa, Lacubegi, Porconis, Peremusta, Selatse, Bandua, Cossus, Nabia, Reva, Neito, Vaelico, Ninimedius, Seddiaqus, Erudinus, Evedutonius, Barciaecus. Dulovius Tabalienus Parameco. Based on the "teonimos" and their study, we present a discussion on the religion and spiritual life of northern Celtic population and Celtiberians in Spain.
\end{abstract}

Palabras clave Teónimos. Hisparia.

Key words Theonimes. Hispania.

Desde 1956 nos venimos dedicando al estudio de las religiones primitivas de la Hispania Antigua (Blázquez, 1962; 1972: 81 ss.; 1973: 705 ss. 1975; 1977; 1979: 1 ss.; 1982: 261 ss; 1987: 69 ss; 1986-87: 141 ss.; 1989; Blázquez, García-Gelabert, 1988: 153 ss.: Encarnaçao, 1975; 1985: 5 ss.). Cada día se acumula nuevo material sobre todo teónimos, que hacen que la primitiva lista hoy día se haya ya casi triplicado. Recientemente se han publicado nuevos estudios y teónimos, que recogemos en este trabajo, con el que queremos rendir fruto homenaje al Dr. Veny, del Departamento de Prehistoria y Arqueología del CSIC, con cuya amistad nos hemos honrado.

$\left.1^{\circ}\right)$ Salvador Haba (1990: 121 ss.) de la Universidad de Extremadura, ha publicado una inscripción,

(*) Universidad Complutense. Madrid. 
que contiene el nombre de un nuevo teónimo, Vortiacio. La inscripción dice así: VORTIA/CIO. AVI/TVS/TICI[(us)] AV/CI((us)) TONC(i) F(ilii) PARRIS / SVI V(otum). S(olvit)/ L (ibens).

Señala la autora que se trata de un voto ofrecido a una divinidad por tres hermanos, cuyos antropónimos presentan el radical $A v i$-, frecuente en la onomástica lusitana. La dedicatoria se debió hacer en nombre del padre. La fórmula ser repite en otra inscripción de Mirabel (Plasencia, Cáceres). Esta ara se halló en Montehermoso (Cáceres). El teónimo está vinculado con un epíteto de una ara lusitana de Salgueiro (Fundao), dedicada a Bandi Vorteaeceo. También se relaciona con el teónimo Vortiaecii de una segunda ara de Penacor (Beira Baixa), en Portugal. Este teónimo se presenta bajo tres formas distintas, Vorteaeco, Vortiaecio y Vortiacio. El radical es el mismo que el teónimo itálico, Vortumnus. La lápida de Montehermoso estaría dedicada a una divinidad del grupo Band. Esta lectura permite interpretar bien la inscripción procedente de Malpartida de Plasencia, leída imperfectamente, que sería Band(di)/ Vor(tiacio) P.../ icio Ca(tu) venus. Aveli f(ilius) v(otum) s(olvit) l(ibens) m(erito).

El dios indigena Vortiacio iria unido, a juzgar por el significado del radical, con la idea de cambio y transformación. Los testimonios de su culto han aparecido en un área muy concreta.

$\left.2^{\circ}\right)$ J. L. Ines (1978: 7 ss.) ha publicado la epigrafía romana de la región de Viseu, Portugal con algún teónimo ya conocido. Es el siguiente: DVATIUS/APINI F (ilius)/BANDIT/ATIDIIAIC/VI VOCTO/TOLIT (iussu).

Este ara se halló en Queriz, concejo de Fornos de Algodres.

$\left.3^{\circ}\right)$ C. Castillo (1990, en prensa; Castillo, Bañales, 1989: 523 ss.) ha catalogado los teónimos indígenas que se leen en la epigrafía navarra. Estos son Larrahi en Andelo. La inscripción reza Manilius Martialis votu(m) retulit Larrahi.

El teónimo Larrasoni de Aquitania se parece mucho al topónimo navarro Larrasoana. Se trataría según esta autora de la versión indígena de Silvanus, muy documentado en territorio pirenaico. El Larrahi de Andelo tiene el mismo origen.

En Larraga, cerca del lugar del hallazgo del ara consagrada a Larrahi, se encontró un segundo teónimo Errensa. La inscripción dice así: D(omitia)Mater. / na Errens---/ ae pro l/(iberis?) o l(ibertate?) $\mathrm{i}$ (ussit)/ L(ucretia) Crista ar/bitrati) suo v(otum) s(olvit). El texto pertenece, posiblemente, a un entorno social de libertos. La interpretación del significado del téonimo por el vasco erreka o erreten, no parece segura, ni tampoco su derivación de Reve. La terminación -nsa se repite en otra divinidad procedente de la provincia de Burgos (Ranera), -Velonsa/Uhlonsa-

Al dios Lacubegi, de Ujué, también tributaron culto libertos. El primer elemento sería de origen latino, lacu- y el segundo vasco, begi-. El primero entra en la formación de topónimos con el significado de pozos, estanques, arroyos. Sería, por lo tanto, Lacubegi un dios de los manantiales, y de las aguas.

Seguramente de Viana procede el teónimo [i]v[a] por(coni), que recibió culto también en Sos del Rey Católico. El elemento Porconis podría ser una variante del aquitano Borconis.

Peremusta, documentado en Eslava y en Rocaforte, lleva apelativo de nombre indoeuropeo, pero los de Peremusta son latinos: Deus Magnus.

El sufijo -st- se encuentra en topónimos de la región alabesa y navarra (Contrasta, Caresta, Bergaristo), y en el teónimo Baelisto.

En los teónimos Selatse, que se lee en tres aras Barbarin, y Loxa, con - $x$ - en Arquiñariz y -s- en Ciranqui, y en Lerate, tendríamos una grafía que responde a una pronunciación de un hablante de procedencia euskera.

La relación de Selatse con Helassa presenta dificultades. Más probable es vincularla con antropónimos aquitanos como Selexse. Para Losa se ha pensado en un origen euskaro, que corresponde al vasco Lotsa, pudor. Sería la personificación de un abstracto indígena, correspondiente a Pudor o Pudicitia.

C. Castillo deduce del estudio de estos teónimos, que son un claro testimonio de un proceso de 
romanización no totalmente cumplido. El número de dioses romanos no es superior a los del panteón indígena. La mayoría de estos últimos no son de procedencia indoeuropea. Sus fieles estaban integrados en la sociedad romana, aunque algunos conservan sus nombres no latinos. Estos nombres indígenas de dedicantes, como Doiterus Bodo, Minicia Annia, son indoeuropeos. En cambio, los teónimos de nombres vascos tienen dedicantes de nombre latino. Se trata, según esta autora, de gentes que mantuvieron los cultos de sus antepasados, aunque ya se encontraban romanizados.

$\left.4^{\circ}\right)$ F. Marco (1990) ha estudiado recientemente el mundo religioso y funerario de las poblaciones célticas de la Hispania Antigua. Defiende este autor que se puede hablar de una religión de los celtas con rasgos específicos, pero no hubo un sistema religioso perfectamente estructurado. Se está generalizando la tesis de la existencia de unos dioses universales caracterizados por la plurifuncionalidad, que se expresa en multitud de deidades de ámbito local, conocidas por la epigrafía. Piensa F. Marco, que la mayoría de los teónimos sólo expresan la veneración local de dioses protectores, como se desprende de los epítetos que aluden al lugar de la vivienda y rara vez a un grupo humano. Acepta este autor la teoría expresada por Hoz y Untermann de que los teónimos más frecuentes en la región galaico-lusitana, como Bandua, Cossus, Nabia y Reva, tendrían un carácter genérico, alusivo a la divinidad. Algunos teónimos, como los del grupo Bandua, serían un claro prototipo de dioses indoeuropeos, en relación con cofradías de guerreros. Cosus sería otro dios de carácter guerrero y su epíteto Oenaecus aludiría a las reuniones de las asambleas que se celebrarían en los santuarios prerromanos al aire libre. Nabia y Reve irían vinculados con conceptos de geografía sagrada y de soberanía guerrera, simbolizando el viaje a la ultratumba a través del agua, y de la llanura del combate. El papel del Marte indígena no quedaba reducido a sus uniones guerreras, sino que tendría una pluralidad de funciones, como protector de la colectividad. Los dioses de Celtiberia tienen un marcado carácter pancéltico, aunque no ha aparecido la triada gala, Teutates, Esus y Taranis. Propone F. Marco que la divinidad innominada, cuyo ritual consistía en danzar en las noches de plenilunio (Str. 3.4.16) ante las casas, podía identificarse con Dis pater. Lug-, bien atestiguado en Hispania y fuera de ella, Irlanda, Bretaña, etc. sería el dios celta más importante. Su santuario al aire libre se encontraba en Peñalva de Villastar (Teruel). Sería un dios de carácter solar y guerrero. Celtiberia veneraba igualmente a Epona y a las Matres. Se conocen en Clunia (Burgos) muchas lápidas a ellas consagradas. Epona es una deidad asociada a los difuntos. Neto (Coimbra y Trujillo) sería un dios de carácter solar y guerrero (Macr. Sat. 1.19.5.). Está mencionado en el bronce de Botorrita como Neito y en Binefar Neitin, nombres todos vinculados con el Neit irlandés. Cernunnos estaría representado en un vaso de Numancia y la serpiente cornuda relacionada con él en un vaso de Arcóbriga. También se veneraría a un dios del tipo Sucellus, de carácter infernal, que aparece en el santuario de Candeleda, bajo el teónimo de Vaelico. Algunas representaciones aludirían a la existencia de cofradías de guerreros en el área lusitano-galaica y en otras. Propone F. Marco que el bandolerismo lusitano podría ser la expresión de razzias iniciáticas de jóvenes para lograr el status social del guerrero.

Los celtíberos celebraban sus rituales al aire libre. El santuario sería un verdadero centro cósmico. Las piletas, oquedades y canalillos de algunos santuarios pudieran utilizarse para los rituales de sacrificios de animales y de purificación. En Picote (Tras-os-Montes) se han recogido huesos de animales. Tornadizos (Avila), tal vez fuera un recinto ritual/cultual, en el que han aparecido más de veinte verracos. El mismo sentido tendría el santuario de Mozhino. Y semejante carácter podrían tener algunos recintos castreños. Las cabezas cortadas no aludirían a sacrificios humanos, sino a una ética agonística. Algunas cabezas pudieran ser de dioses (Guimaraes). Los suovetaurilia están atestiguados en Cabeço das Fraguas, y en los carros votivos de Costa Figueira y de Castello Moreira, ambas localidades en Portugal. El sacrificio de caballos entre las tribus del norte tiene paralelos en otros pueblos.

Cree F. Marco que Olíndico podría ser un sacerdote. En las pinturas de Numancia aparecen representados sacrificadores. Estos sacerdotes cabe la posibilidad de que fuesen semejantes a los encargados de las adivinaciones en Lusitania. El rito céltico peninsular, referente a enterramiento, 
era la incineración. Las "piedras formosas" pudieran ser baños, según la tesis de Ferreira de Almeida, que aceptaron A. Blanco y F. Marco. Admite este último autor la tesis de G. López Monteagudo del carácter funerario de los verracos. Otras veces estos animales van asociados a santuarios, como en Tornadizos.

Los textos de Eliano (de nat. anim. 10.22) y de Silio Itálico (Pun. 3.340-343) referentes a que los cadáveres de los guerreros se dejaban a la intemperie para que se los comieran los buitres, probarian la creencia en una inmortalidad entre los celtiberos. De esta creencia hay confirmación arqueológica en las estelas de Lara de los Infantes, Zurita, El Palao (Teruel) y Binéfar (Huesca).

Se ha supuesto por Sopeña que el rito de exposición del cadáver indicaría la culminación de un sistema basado en la ética del honor, que da importancia al desafío en el combate, a la vinculación del arma con el guerrero, a la decapitación del guerrero vencido, y a la androfagia por los buitres. Estos animales sería sagrados e integrarían al hombre en lo divino. Otros monumentos indicarían la heroización ecuestre. A jefes indígenas heroizados pertenecerían las esculturas de guerreros lusitanos. La exaltación de la guerra estaría también representada en la procesión de jinetes de la diadema de San Martín de Oscos, bien estudiada en su significación por G. López Monteagudo.

Hasta aquí el pensamiento de F. Marco, que encontramos plenamente aceptable.

En un segundo trabajo ha estudiado F. Marco la iconografía de un vaso hallado en Arcóbriga que había pasado desapercibido. En él se representa una estructura arquitectónica, con dos columnas y bóveda, dentro de la cual se encuentra una figura humana de pie, de la que sale un árbol. En la parte central de la composición se encuentran dos serpientes cornudas y sendos gallos afrontados en la parte inferior. La simbología astral está presente en los crecientes lunares y en el disco solar. Se interpretó esta figura como una representación de Baal Thamar, dios-palmera, de la fecundidad del mundo fenicio. Sería, pues, una prueba de la influencia fenicia entre los pueblos de la Meseta. Figuras humanas asociadas a árboles se documentan en la cerámica de Numancia y en la terra sigillata. El árbol desempeñaria un papel importante en la mentalidad religiosa de la Celtiberia. Recoge el autor una serie de textos que aluden al árbol en la mentalidad religiosa de los celtas y la relación del druida con el árbol.

En el vaso de Arcóbriga se representaría un hombre-árbol, que expresaría la idea de polaridad cósmica. Las columnas reforzarían el contenido semántico del eje cósmico. Sería otra versión del árbol de la vida. Las hojas de hiedra que cuelgan de los capiteles simbolizarían la inmortalidad. La serpiente cornuda reaparece en alguna estela de Lara de los Infantes (dos ejemplares), monumentos funerarios de Clunia, Urbiola (Navarra), Lombera y Monte Cildá. La serpiente significaría la transformación temporal, la fecundidad totalizante híbrida. Sería un animal funerario ctónico, encarnación del difunto heroizado. Los gallos tienen simbolismo solar. Aparecen también en el Soto de Medinilla y en Numancia, aquí asociados al carnero. Las serpientes cornudas son una estilización de los ofidios, con cabeza de carnero, todo con significado de fuerza agresiva. En el Caldero de Gundestrup conduce al Más Allá a los guerreros. En este caldero va asociada a Cernunnos. Otras veces se vincula al gallo.

Las figuras del vaso de Arcóbriga probarían la pervivencia de las creencias religiosas indígenas en época ya romana.

A. J. Domínguez Monedero (1985: 53 ss.) ha analizado recientemente el carácter de los dioses indígenas del norte de Hispania.

Comienza el autor su trabajo señalando que la pervivencia de los dioses indígenas está en relación inversa de la romanización. La ausencia de los teónimos en determinadas áreas vendría motivada, según este autor, "a la propia forma de entender su vida espiritual los habitantes de dichas áreas». Estudia A. J. Domínguez Monedero principalmente la zona costera de la cornisa septentrional de Hispania, entre el río Navia o la sierra de Rañadoiro, por el Occidente, hasta el río Asón, hasta la Peña de Amaya por el Oriente, y la Cordillera Cantábrica por el sur, o sea el área ocupada por los astures y los cántabros. Los teónimos documentados en la epigrafía en esta área son: Ninimedius Seddiagus (Ujo), Erudinus (Pico de Dobra), Evedutonius barciaecus (Naraval), Dulovius tabalienus (San Vicente de Grases) y Parameco. Del número de estos dioses se desprende 
que en una amplia zona del norte no hay constancia de nombres de dioses. Al revés sucede en la Asturia augustana. El texto de Estrabón (3.4.16) que dice que los galaicos son ateos, hay que interpretarlo que los dioses son anicónicos. No es partidario A. Domínguez Monedero de la tesis que interpreta este pasaje como que el nombre de los dioses era tabú. Piensa el autor que este texto no se refiere a los galaicos, sino a los astures y cántabros. Los cántabros y los astures transmontanos serían los que no tienen imágenes de dioses, y sí un dios innominado de carácter lunar. Entre éstos el nombre del dios sería tabú, como se desprende de la ausencia de inscripciones con teónimos.

El párrafo de Estrabón (3.3.7) que habla de que los pueblos del norte sacrifican a Ares machos cabríos, prisioneros y caballos... lo interpreta este autor en el sentido de que el dios indígena tenía el mismo carácter del Ares griego, que no tenía nombre, o que su nombre era tabú. Su carácter sería guerrero. Algunos autores han pensado que Ares sería el dios de la tribu cántabra o astur, que no sería un menor círculo político, sino también religioso y social, y por eso tenía un dios propio, diferenciado de los dioses locales, y sería el dios innominado. Habría, por lo tanto, varios nombres, Ares sería el dios principal. No es partidario A. Domínguez Monedero de que este dios fuera Cosus, o Esus o Teutates. Lucano y Lactancio (Div. Ins. 1.21) hablan de sacrificios humanos a Teutates, Esus y Taranis lo que convendria con unas divinidades asociadas al Ares peninsular, al igual que el Marte céltico se vincula con los caballos. Defiende este autor el carácter no céltico de la religión de cántabros y astures transmontanos. De todo ello se desprende que esta divinidad cántabra tenía un nombre tabú, y que había similitud en los ritos religiosos de los distintos pueblos.

Del ritual seguido en el culto a este dios se derivan varias posibles conclusiones, como la existencia de un rito que propiciase la ganadería por magia simpatética.

El sacrifico de los caballos no podía aludir el carácter vivificador de este animal, que se desprende de la bebida de su sangre. El caballo también va unido a creencias de tipo astral y de ultratumba. Los sacrificios de caballos estaría en función de la protección del caballo y del jinete. El sacrificio de prisioneros confirmaría el carácter astral de esta divinidad. El Ares tendría atribuciones, pues, polivalentes, pero inseparables. El ritual de las danzas en las noches de plenilunio no tiene que ser celebrado necesariamente en honor de la luna, aunque es problable que así fuera por celebrarse el ritual de las danzas precisamente en las noches de plenilunio. Esta divinidad de carácter lunar era también agrícola y protectora de la fecundidad, y se vinculaba con ideas de ultratumba. La religión de estos pueblos sería muy sencilla. Serían divinidades agrícolas, ganaderas y guerreras. La bebida de la sangre de los caballos, de la que hablan Horacio (Carm. 4.33-34 y Silio Itálico (Pun. 3360.361), tendría un carácter mágico. Sus cualidades pasarían a los que la bebieran.

La carne de cabra (Str. 3.3.7) sería, quizás, la de los animales sacrificados. Este ganado sacrificado podría ser robado al enemigo. A. Domínguez Monedero interpreta el texto de Estrabón (3.3.7) en el sentido de que la tercera parte del año, en que no comían los habitantes bellotas, comerían los animales sacrificados al dios, en número muy elevado, hecatombes, y beberían la sangre de los caballos. Piensa este autor (Str. 3.3.7) que la forma de comer descrita por el geógrafo de Amasea no era la habitual, sino la celebrada en ocasiones especiales. Este autor propone la siguiente interpretación de este texto. Se reunía toda la comunidad bajo la presidencia de un jefe, a cuyo lado se sentaban los jefes de las unidades familiares. La comida tendría un carácter ritual, como lo indican las danzas, que quizás sean guerreras. La comida sería ritual, al estar el animal sacrificado al dios. También otros dioses recibirían culto. Todo estaría impregnado de dioses y por eso no haría falta representarlos. Los dioses innominados pueden ser también anicónicos. En las comidas celebradas en honor de Ares participarían las personas más destacadas, y en los rituales a la luna todo el mundo. El ateísmo de estos pueblos, probablemente, es un animismo sustituido lentamente por una divinidad sin nombre, sin concreción, ni manifestación material. Conviven rituales dedicados a las divinidades, que no se identifican de manera segura con otras conocidas. La interpretación de A. Domínguez Monedero es aceptable, por saber por las fuentes irlandesas que las reuniones rituales de los celtas iban seguidas de comidas, de bebidas, de juegos o de carreras. Después de mencionar las hecatombes en honor de Ares, añade Estrabón (3.3.7) "practican luchas gímnicas, hoplíticas e hípicas, ejercitándose en pugilato, la carrera, las escaramuzas y las batallas campales», que proba-

T. P., 1991, $\mathrm{n}^{0} 48$ 
blemente formaban parte del ritual. La escasez de testimonios epigráficos se debe al hecho de encontrarse estas gentes muy alejadas de los influjos romanos.

Estas nuevas interpretaciones de los textos de Estrabón propuestas por A. Domínguez Monedero, son muy ingeniosas, deben ser tenidas en cuenta en el futuro y discutidas.

F. Marco ha estudiado la individualización del espacio sagrado en el noroeste hispánico.

Parte el autor de la inscripción hallada en Vercellae en 1966, redactada en latín y céltico, fechada hacia el año 100 a. C., en la que se dice que Akisios Arkatokum Aterekos dispuso cuatro mojones terminales para delimitar un espacio de terreno, que donó para que fuera "común a los dioses y a los hombres". Se trata del espacio cultual, que simboliza la unidad mística de dioses y hombres, que preside el orden cósmico, idea clave de la religión de los celtas. Este espacio recibe el nombre de nemeton. Estos recintos cultuales cuadrangulares se documentan en Francia, Alemania e Inglaterra. Se fechan en el siglo I a. C., y remontan a los recintos funerarios de la Edad del Hierro y se prolongarían en los templos galorromanos de planta circular o cuadrada. Estos nemeton eran o islas en el mar o bosques sagrados o la cumbre de montañas o claros del bosque. En ellos los druidas impartían sus enseñanzas. Eran el locus cosecratus de los escritores clácicos. Algunos autores son de la opinión de que también eran los grandes recintos donde se celebraban las reuniones estacionales de los tuah y los santuarios de menor importancia. Se conocen topónimos formados sobre esta palabra, como Mediolanum. Las formaciones sobre el término nemeton son conocidas en Galatia, Norico, Britania, Galia y Germania. En Hispania, Ptolomeo (2.6.40) menciona a los nemetati, a los que pertenecía la ciudad de Nemetobriga en el conventus astur. Marcial cita la fuente Nemeta. También nemeton entra en la formación de teónimos hispanos, de los que el más conocido es Nimmedo Seddiago, fechado a comienzos del siglo II. El radical del teónimo es el mismo que entra en Nimmmedus Seddiagus, podría ser equivalente a sedatus, con la significación de Nimmedo asentado aquí. La segunda inscripción hispana importante sería la grabada en la roca de Bonça de Capitao de Fervança, de lectura dudosa. Se ha propuesto la lectura de (Nimid o Niminid) Fiduenearum hic/et Cornuae h.s., alusiva al santuario de las divinidades Fidueneas. El hecho de que la inscripción esté escrita en una roca parece reforzar la interpretación de que se trata de un nemeton, como también se desprende de la significación de Fiduenearum del bosque. En Castelo de S. Jorge de Lisboa Pflaum leyó Nemetius o Nemetia, lectura incierta, pues Encarnaçao cree que se trata de un antropónimo. En Burgaes (Portugal) es probable que recibiera culto también Nemeoeco.

De todos estos datos se puede deducir que en el norte hispano recibió culto una deidad relacionada con una noción universal de los celtas, el nemeton.

La tesis expuesta en este artículo por F. Marco es perfectamente aceptable. También este autor alude al carácter luminoso que tenía Marte entre los celtas atestiguado en Hispania por el conocido texto de Macrobio, referido a Neto, dios de los accitanos de Guadix.

\section{BIBLIOGRAFIA}

Blázouez, J. M. (1962): Religiones primitivas de Hispania I. Fuentes literarias y epigráficas. Ediciones Cristiandad. Madrid.

- (1972): «Ultimas aportaciones a las religiones primitivas de Hispania». Homenaje a Antonio Tovar: 81-92. Madrid.

- (1973): «Die Mythologie der Alhispanier, Wöterbuch der Mythologie». Götter und Mythen im Alten Europa: 25-51. Sttuttgart.

- (1975): Diccionario de las religiones prerromanas de Hispania. Ediciones Cristiandad. Madrid.

- (1977): Imagen y mito. Estudios sobre religiones mediterráneas e ibéricas. Ediciones Cristiandad. Madrid.

- (1979): "Ultimas aportaciones a las religiones primitivas de Hispania». Estudios dedicados a Carlos Callejo Serrano: 1-20. Cáceres.

- (1982): Historia de España. España romana. Espasa Calpe, S.A., Madrid.

$$
\text { T. P., 1991, n } 48
$$


- (1986-87): «Nuevos teónimos hispanos (Addenda et Corrigenda)». Cuadernos de Prehistoria y Arqueología 13. 14. Homenaje al Prof. Gratiniano Nieto. Vol. II: 141-162.

- (1987): «Recientes aportaciones a las religiones primitivas de Hispania (Addenda et Corrigenda)». ATHLON. Satura grammatica in honorem Frascisci $R$. Adrados. II: 69-82. Madrid.

- (1989): Primitivas religiones ibéricas II. Religiones prerromanas. Ediciones Cristiandad. Madrid.

Blázouez, J. M. y García-Gelabert, M. P. (1989): «Nuevas aportaciones a las religiones primitivas de Hispania». Espacio, Tiempo y Forma. Historia Antigua. Homenaje al Prof. Eduardo Ripoll Perelló. II. 1: 153-183. Universidad Nal. Educación a Distancia. Madrid.

CASTILlo, C. (1990): "Teónimos indigenas en la epigrafía Navarra». II. Congreso General de Historia de Navarra. Pamplona.

Castillo, C. y Bañales, J. M. (1989): «Epigrafía romana en Andión y su entorno». Príncipe de Viana, 188: 523-534.

DomíngueZ, A. (1985): "Algunas interpretaciones en torno a la religiosidad de los pueblos prerromanos del área cántabro-astur». In Memoriam Agustín Díaz de Toledo: 53-64. Universidad de Granada.

EnCARnaÇAO, J. (1975): Divinidades indigenas sob o dominio romano em Portugal Lisboa.

- (1985): «Divinidades indígenas de Lusitania». Conimbriga, 26: 5-25.

HABA, S. (1990): «La divinidad Vortiacio: nuevos testimonios epigráficos hallados en la provincia de Cáceres». Alcántara, 19: 121-130.

INES, J. L. (1978): Epigrafía romana de assembleia distrial de Viseu. Viseu. 